\title{
DISTRIBUTED ADMISSION CONTROL OF VIDEO ON DEMAND SERVICES OVER EXISTING TELEPHONE NETWORKS
}

\author{
Md. Shamsul Alam, Md. Mahmudul Hasan, and M. N.I. Mondal \\ Department of Computer Science \& Engineering \\ Rajshahi University of Engineering \& Technology
}

\begin{abstract}
The transmission of multimedia streams with a particular and guaranteed quality of service (QoS) is a major challenge in multimedia communication over IP networks. In this paper, we analyze the distributed architecture of a Video on Demand (VoD) system to design global request handling and admission control strategies. We describe a highly available distributed VoD service using existing telephone network, which is inherently scalable and fault tolerant. The VoD service is provided by Media Server Farms (MSF), which may reside in different local telephone exchange of a telephone network. We present the design and simulation results for a new distributed admission control and QoS adaptation controller architecture, called SemiDistributed Admission Control (SD-AC) architecture for a set of MSFs.
\end{abstract}

\section{INTRODUCTION}

The explosive increase in commercial usage of the Internet has resulted in a rapid growth in demand for video delivery techniques over Internet. Distributed VoD systems are expected to be one of the most important services supported by the next generation of high speed networks, video servers, and distributed multimedia file systems. If a network with finite resources practices promiscuous admission by admitting all multimedia requests, it is impossible to absolutely guarantee QoS, as resources become over-committed. Consequently, to provide QoS guarantees to the admitted sessions and to sustain good quality of service for prolonged periods of time, some form of admission control is mandatory.

Considerable work has been done in recent years on transmission of video streams and other multimedia information [1-3]. Delivery of multimedia streams with absolute guaranteed QoS from a single multimedia server has been proposed by Khan [4]. He proposed the Utility Model for admission and adaptation of session in a multi session multimedia service provider. But this model treats only a single server system and does not handle huge amount of data and participants. Akbar [5] presented Centralized Admission Control (C-AC) architecture, which utilizes centralized computing performed by a broker. This architecture faces load-balancing problem with the increase of users. Alam [6] described Fully Distributed Admission Control (FD-AC) and QoS adaptation scheme for multimedia servers and networks. In this approach all controllers can receive request from clients and run collectively to maximize the revenue in the distributed system. This architecture suffers messagepassing complexity for huge number of customers. Gibbens [7] have looked at distributed connection admission control with an edge device acting as a gateway to determine whether to accept a connection or not. This approach does not provide fault tolerance.

The main contribution of this paper is a distributed model of media servers for VoD service and distributed controller architecture to do admission control and QoS adaptation for distributed multimedia service. This paper also presents a comparison between C-AC, FD-AC and SD-AC architectures. To analyze the performance of different admission control architectures, we present a simulation of admission controllers of MSFs.

\section{DISTRIBUTED ADMISSION CONTROL}

To reject some of the applicant sessions when insufficient resources are available to serve all of them, some form of admission control is necessary. Maximization of revenue by admitting profitable sessions is an important objective of the admission controller. In this paper we present novel SD-AC and QoS adaptation architecture.

\section{PROPOSED SD-AC AND QOS ADAPTATION ARCHITECTURE}

In this approach, each MSF is connected with a Local Controller (LC) and all the LCs are interconnected through a Central Controller (CC) for negotiation among them shown in figure 1. Only the LC of a MSF has the 
authority to allocate resources of the servers providing VoD services to the users. Each LC keeps the record of available resources of the corresponding media servers. Users are required to communicate with (one of) the local admission controllers to submit their requests and to receive admission or rejection decisions made by the controllers.

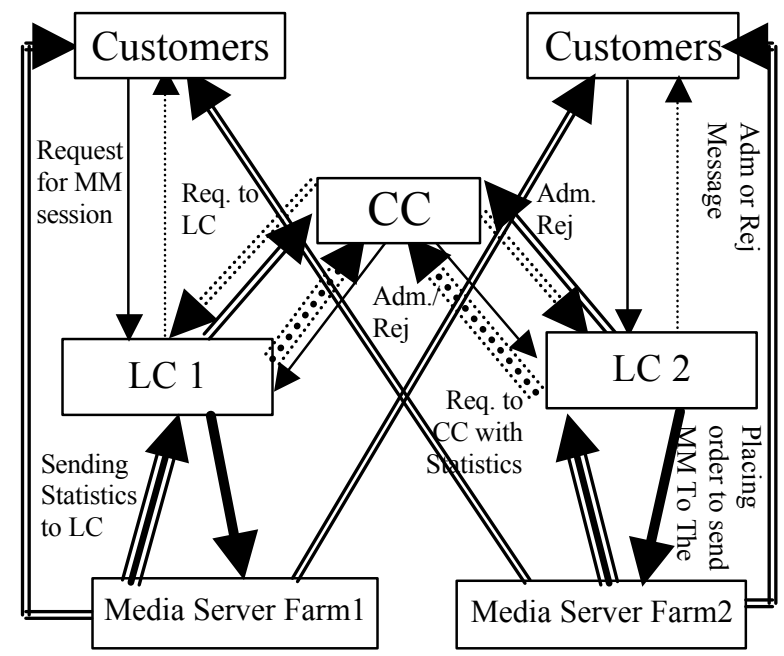

Figure.1: Message flow diagram of SD-AC architecture

Users send their movie request to the $\mathrm{LC}$ and get an admission depending on the movie availability and resource required for that particular movie. If the local server fails to give video streams then it forwards the request to the $\mathrm{CC}$, which first checks the resource statistics of all other LCs and selects an appropriate LC for a particular movie request and finally sends the admission request to the possibly appropriate LC or rejection message to the requesting user.

\section{ADMISSION CONTROL AND QoS ADAPTATION METHODOLOGY}

New sessions are collected into a batch over a time interval. A single batch of session sends to LC or CC's Admission Control algorithm. This algorithm accepts or rejects each session in the batch using QoS adaptation methodology. A session consists of user address, movie no, sender LC no., time stamp, etc. When the algorithm selects a session to be accepted or rejected, it starts checking whether this session's requested movie resides in this MSF's allocated servers, controlled by current LC. If satisfies, the algorithm tries to offer from highest QoS level to a lower one, for the session request according to the allocated servers resource statistics, which later maximizes the total earned revenue. The accepted session is then added with new features, like allocated QoS level, allocated server, receiver LC no., whether the rejected session is added with no new features, though they need to be considered for revenue calculation.

\section{SIMULATION OF ADMISSION CONTROLLER}

We simulate the admission controllers of the set of Media Server Farms for different distributed admission control architectures using linear programming approach. The performance data has been collected by varying the number of users and the number of video servers. The table $1-4$ presents the parameters of the set of MSFs required for the simulation.

We have coded the simulation of the LC \& CC using the Java programming language (JDK ver 1.3). LC generates a big batch of user session request initially, having double size of Media Server Farm's server resource capacity, to get admission for creating contention of resources in the resided servers. We have discarded 10 percent of accepted sessions to create space for future sessions, then generate 15 percent new sessions as a small batch. The total simulation ends when all LCs have generated 100 batches. We calculate the revenue earned from the users and the time required by LC to do admission control and QoS adaptation. The summation of the revenues of the sessions and average time requirement by each session is the measure of the distributed admission controller's performance in our simulation. We run the simulation on a $1.7 \mathrm{GHz}$ Pentium IV Windows XP LAN with 128MB RAM.

Table 1:Different simulation parameters

\begin{tabular}{|l|l|l|l|l|l|l|l|l|l|}
\hline \multicolumn{1}{|c|}{ Parameter } & \multicolumn{7}{|c|}{ Value(s) for the Simulation } \\
\hline Maximum length of movie & \multicolumn{10}{|l|}{3 hours } \\
\hline $\begin{array}{l}\text { Total Number of movies in } \\
\text { MSF }\end{array}$ & \multicolumn{10}{|l|}{10} \\
\hline $\begin{array}{l}\text { Number of video servers in } \\
\text { MSF }\end{array}$ & 5 & 10 & 15 & 20 & 25 & 30 & 35 & 40 & 45 \\
\hline $\begin{array}{l}\text { Number of replications of } \\
\text { video }\end{array}$ & 3 & 3 & 3 & 4 & 5 & 6 & 7 & 8 & 9 \\
\hline $\begin{array}{l}\text { Number of movie copies per } \\
\text { server }\end{array}$ & 6 & 3 & 2 & 2 & 2 & 2 & 2 & 2 & 2 \\
\hline $\begin{array}{l}\text { Repetitions of the } \\
\text { simulation experiment }\end{array}$ & 5 & \multicolumn{10}{|l|l|}{} \\
\hline
\end{tabular}

Table 2: Initialization of server resources in the MSF

\begin{tabular}{|c|c|c|c|}
\hline $\begin{array}{l}\text { Type of } \\
\text { resource }\end{array}$ & $\begin{array}{c}\text { Server } \\
\text { resource } \\
\text { value }\end{array}$ & $\begin{array}{c}\text { Initialization } \\
\text { function for a video } \\
\text { server }\end{array}$ & Assumptions \\
\hline CPU & $\begin{array}{l}400 \mathrm{MHz} \\
\text { dual } \\
\text { processor }\end{array}$ & $\begin{array}{l}100 \mathrm{X} U(0.95 \\
1.05)\end{array}$ & $\begin{array}{l}\text { Total } 800 \mathrm{MHz} \text { is } \\
\text { equivalent to } 100 \\
\text { cycles. }\end{array}$ \\
\hline RAM & $256 \mathrm{MB}$ & $\begin{array}{l}120 \mathrm{X} \mathrm{U}(0.95, \\
1.05)\end{array}$ & $\begin{array}{l}136 \mathrm{MB} \text { is used by } \\
\text { the } \mathrm{O} / \mathrm{S} \text {. }\end{array}$ \\
\hline Bandwidth & $640 \mathrm{Mbps}$ & $\begin{array}{l}600 \times \mathrm{X}(0.95, \\
1.05)\end{array}$ & $\begin{array}{l}40 \mathrm{Mbps} \text { is reserved } \\
\text { for the system. }\end{array}$ \\
\hline
\end{tabular}


Table 3: Different QoS levels supported by the DVoDS

\begin{tabular}{|l|l|l|l|l|l|}
\hline $\begin{array}{l}\text { QoS } \\
\text { levels }\end{array}$ & $\begin{array}{l}\text { Average } \\
\text { I/O BW } \\
\text { req. }\end{array}$ & $\begin{array}{l}\text { Average } \\
\text { CPU } \\
\text { cycles req. }\end{array}$ & $\begin{array}{l}\text { Average } \\
\text { Memory } \\
\text { req. }\end{array}$ & $\begin{array}{l}\text { Average } \\
\text { offered } \\
\text { price by } \\
\text { the user }\end{array}$ & $\begin{array}{l}\text { Average } \\
\text { cost of } \\
\text { providing } \\
\text { media }\end{array}$ \\
\hline $\begin{array}{l}\text { QoS 1 } \\
\text { Bronze) }\end{array}$ & $\begin{array}{l}1.5 \\
\text { Mbps }\end{array}$ & $0.25 \%$ & $0.3 \mathrm{MB}$ & $\$ 1.0$ & $\$ 0.75$ \\
\hline $\begin{array}{l}\text { QoS 2 } \\
\text { (Silver) }\end{array}$ & $\begin{array}{l}3.0 \\
\text { Mbps }\end{array}$ & $0.50 \%$ & $0.6 \mathrm{MB}$ & $\$ 3.0$ & $\$ 2.25$ \\
\hline $\begin{array}{l}\text { QoS 3 } \\
\text { (Gold) }\end{array}$ & $\begin{array}{l}4.5 \\
\text { Mbps }\end{array}$ & $0.75 \%$ & $0.9 \mathrm{MB}$ & $\$ 5.0$ & $\$ 3.75$ \\
\hline
\end{tabular}

Table 4: Initialization of resource requirements for different QoS levels

\begin{tabular}{|l|l|}
\hline Parameter & Initialization function \\
\hline $\begin{array}{l}\text { I/O bandwidth requirement for the } \\
\text { kth QoS level }\end{array}$ & $1.5 \mathrm{X} \mathrm{k} \mathrm{X} \mathrm{U}(0.75,1.25)$ \\
\hline $\begin{array}{l}\text { Memory requirement for the kth } \\
\text { QoS level }\end{array}$ & $0.3 \times \mathrm{k} \mathrm{X} \mathrm{U}(0.75,1.25)$ \\
\hline CPU cycles for the kth QoS level & $0.25 \mathrm{X} \mathrm{k} \mathrm{X} \mathrm{U}(0.75,1.25)$ \\
\hline $\begin{array}{l}\text { Offered price by a user for the kth } \\
\text { QoS level }\end{array}$ & $(2 \mathrm{k}+1) \mathrm{X} \mathrm{U}(0.75,1.25)$ \\
\hline $\begin{array}{l}\text { Cost of providing kth QoS level of } \\
\text { a movie }\end{array}$ & $(2 \mathrm{k}+1) \mathrm{X} \mathrm{U}(0.55,0.95)$ \\
\hline
\end{tabular}

\section{SIMULATION RESULTS AND DISCUSSION}
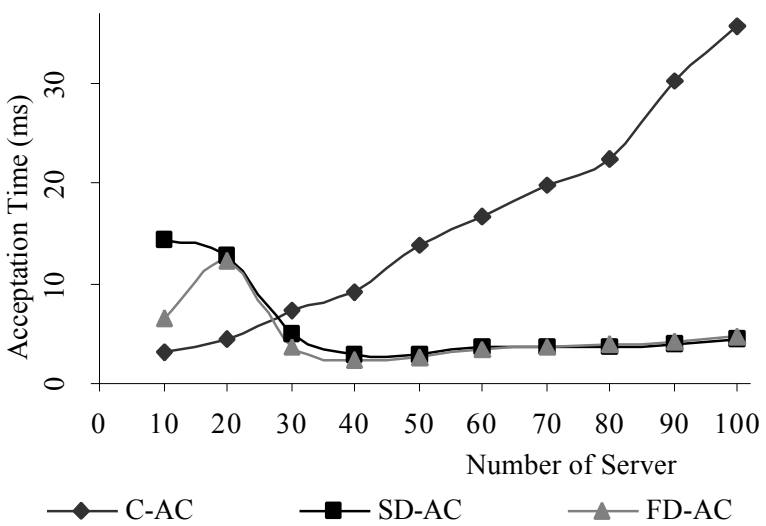

Figure 2: Average acceptation time for different number of servers.

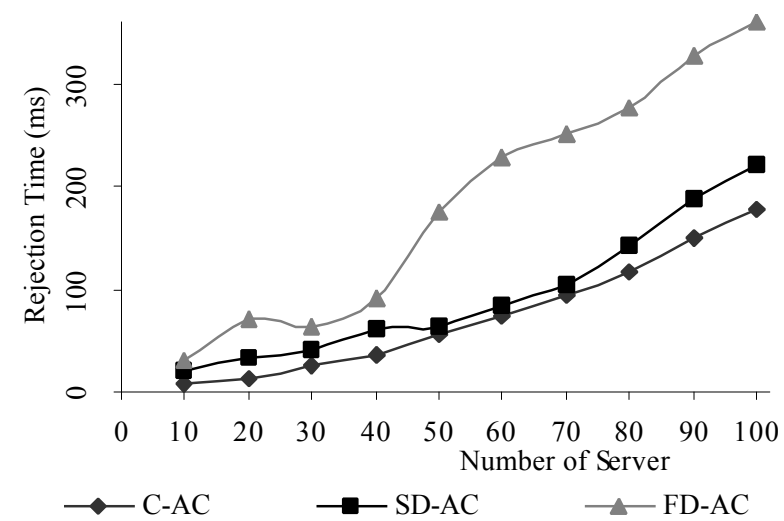

Figure 3: Average rejection time for different number of servers.

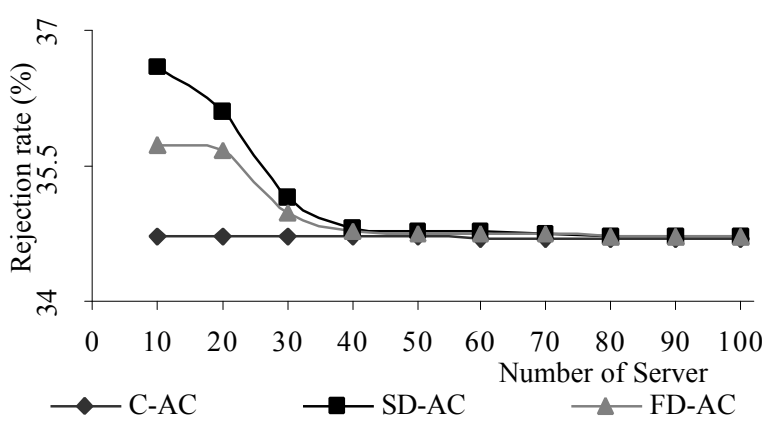

Figure 4: Rejection rate for different number of servers.

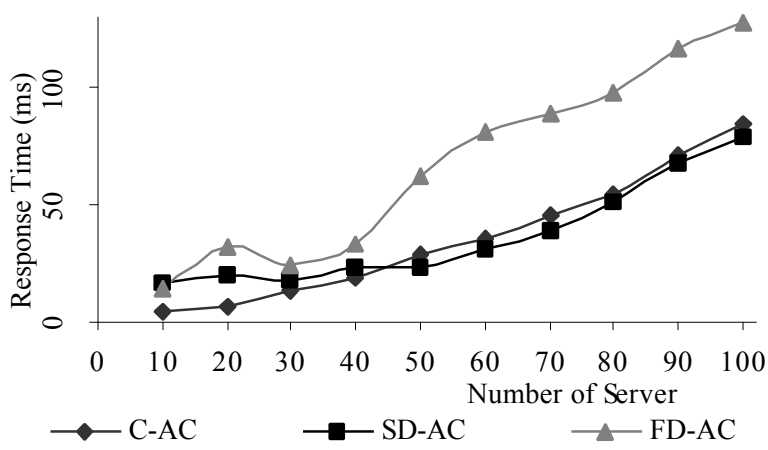

Figure 5: Average response time for different number of servers.

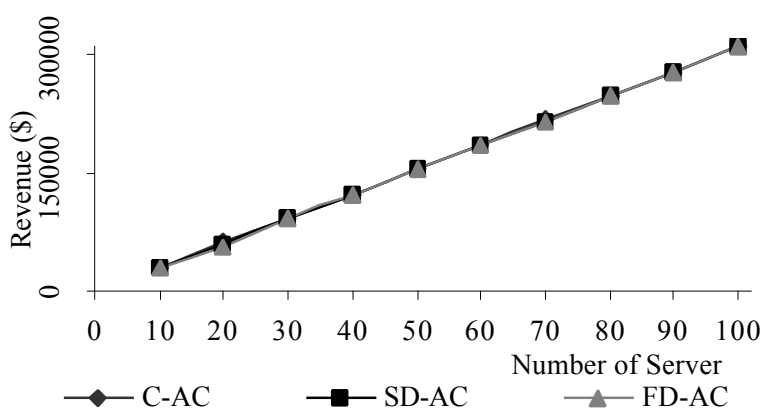

Figure 6: Total revenue earned for different number of servers.

Figure 2 shows that the average acceptation time increases as the number of server increases in $\mathrm{C}-\mathrm{AC}$ architecture but reduces rapidly in SD-AC and FD-AC architecture. This is because the total workload is distributed among the LCs in SD-AC and FD-AC. It is also observed form fig. 1 that initially acceptation time is higher in SD-AC, but it decreases as the number of server increases and it is nearly straight line after 30 servers. This phenomenon states that $\mathrm{SD}-\mathrm{AC}$ is more scalable than C-AC. This is due to the fact that acceptation by $\mathrm{CC}$ reduces with the increase of servers.

Figure 3 depicts that SD-AC architecture has slightly higher rejection time than $\mathrm{C}-\mathrm{AC}$ architecture. The reason is in the $\mathrm{SD}-\mathrm{AC}$ architecture all the temporally rejected sessions are forwarded to $\mathrm{CC}$ for further admission by other LCs. So, it takes long time to 
get rejection decision from CC. Normally the time requirement for $\mathrm{CC}$ acceptation or rejection is four times higher than local acceptation in case of SD-AC architecture. We also observe that FD-AC architecture has higher rejection time than SD-AC and C-AC architectures because any session in FD-AC is rejected only when all other LCs fail to provide video stream for a particular request and therefore communication cost increases.

The rejection rate of SD-AC and FD-AC architecture is initially high, but decreases quickly as the number of server increases and merged with the $\mathrm{C}-\mathrm{AC}$ architecture after 40 servers shown in fig. 4 . This is because as the number of server increases, there is less resources contention in the system.

Figure 5 illustrates the over all response time of different admission control architectures. For all admission control architectures, the response time increases if the number of server increases, due to extra search among larger number of servers. In case of SD$\mathrm{AC}$ initially the response time is higher than $\mathrm{C}-\mathrm{AC}$, but after 40 servers the SD-AC architecture has the lowest response time. So for a large VoD system our proposed $\mathrm{SD}-\mathrm{AC}$ architecture is better and efficient.

From figure 6, we observed that the earned revenue for all the architectures is merged and each curve follows the same line. In each architecture, earned revenue increases as the number of server increases, because large number of server has greater amount of resources.

So, from the above observations and discussion, we can conclude that for the large $\mathrm{VoD}$ system, our proposed SD-AC architecture is superior to its competitors because it is more fault tolerant than $\mathrm{C}-\mathrm{AC}$ and it has less messages passing complexity than that of FD-AC architecture.

\section{CONCLUSION}

In this paper, we analyzed the performance of different distributed admission control architectures. We have presented a new model for admission control and QoS adaptation architecture which addresses the issues of optimal admission of user requested sessions, server failures and scalability. These are the key features of video on demand service. This new architecture has less message passing, limited interconnections, better fault tolerant and computation overhead centralization over C$\mathrm{AC}$ and FD-AC architecture. New distributed admission control algorithms for solving the model were presented and applied in simulated implementations of optimal admission controllers. This model gives optimal strategy of admission control for selecting servers and QoS level for a set of multimedia session request. The concepts presented in this paper may be exploited in a highly available VoD service for hotels and residential neighborhoods and earned significant amount revenue in the near future.

\section{REFERENCES}

[1] K. A. Hua, M. A. Tantaoui, and W. Tavanapong, "Video delivery technologies for large-scale deployment of multimedia applications," IEEE Trans. on Multimedia, vol. 92, no. 9, pp. 1439-1451, Sep. 2004.

[2] P. Mundur, R. Simon, and A. K. Sood, "End-to-end analysis of distributed video-on-demand systems," IEEE Trans. on Multimedia, vol. 6, no. 1, pp. 129141, Feb. 2004.

[3] G. Kola, T. Kosar, and M. Livny, "A fully automated fault-tolerant system for distributed video processing and off-site replication," in Proc. the $14^{\text {th }}$ International Workshop on Network and Operating Systems Support for Digital Audio and Video, Cork, Ireland, pp. 122-126, June 16-18, 2004.

[4] S. Khan, K. F. Li, and E. G. Manning, "The utility model for adaptive multimedia systems," in Proc. International Conference on Multimedia Modelling, Singapore, pp. 111-126, Nov. 17-20, 1997.

[5] M. M. Akbar, E. G. Manning, and G. C. Shoja, "Admission control and QoS adaptation in distributed multimedia server system," ITCom 2001, Denver, USA, Aug. 2001.

[6] M. S. Alam,and M. W. Haque, "A Fully Distributed Architecture of Video On Demand Services," $3^{\text {rd }}$ International Conference on Electrical, Electronics and Computer Engineering, ICEECE-2003, Dhaka, Bangladesh, December,2003.

[7] R. J. Gibbens and F. P. Kelly, " Distributed connection acceptance control for a connectionless network," in Telletrafic Engineering in a Competitive World, Proc ITC16, Eds; Elsevier, June 1999, pp. 914-952.

[8] Md. Naimul Basar, Md. Shamsul Alam, \& Md. Mostofa Akbar, "Semi - Distributed Admission Controller Architecture Of Video On Demand (Vod) Service For A Set Of Media Server Firms," In Proc. of $3 \mathrm{rd}$ International Conference on Electrical \& Computer Engineering, ICECE 2004, 28-30 December 2004, Dhaka, Bangladesh 